\title{
EL CUERPO Y SUS EXPRESIONES PATOLÓGICAS EN EL DEVENIR CONTEMPORÁNEO DE LA INFOESFERA
}

\author{
THE BODY AND ITS PATHOLOGICAL \\ EXPRESSIONS IN THE CONTEMPORARY \\ DEVELOPMENT OF THE INFOSPHERE
}

\author{
BORJA GARCÍA FERRER* \\ Universidad de Granada
}

Resumen: Hablar del nuevo malestar en la cultura que nos hostiga es hacerlo de un inquietante huésped que entra y sale, clandestinamente, por todas partes. Pero por mucho que se trate de una realidad inescrutable por definición, el ascenso imparable de enfermedades sociales en los últimos tiempos no deja lugar a dudas. En el presente trabajo, abordamos el papel que juegan las nuevas tecnologías de la información y la comunicación (NTIC) al respecto, crucial en la medida que simulan in distans un mundo que no es mundo alguno. Encapsulado en este sentido, la actualidad del cuerpo y sus expresiones en el devenir contemporáneo de la tele-comunicación radica en el desarraigo y la errancia, hasta el punto que los profusos dispositivos de la técnica consumada nos resultan actualmente más familiares que el sentido del mundo que nos ha visto nacer.

Palabras Clave: Nuevas tecnologías de la información y la comunicación, «comunicación instantánea», «bombardeo semiótico», desarraigo, errancia.

Aвsтract: Dealing with the new uneasiness in culture that plagues us means talking about a disturbing undercover guest who appears and disappears everywhere. But

* Dirección postal: C/ Pedro Temboury, No31, P-2, $1{ }^{\circ}$ C, C.P.: 18013 , Granada. E-mail: borja co@hotmail.com. Este artículo reproduce y amplía el contenido de la comunicación pronunciada por el autor el 6 de noviembre de 2012 en Granada, con ocasión del Congreso Internacional El Cuerpo y sus Expresiones, organizado por el Centro Mediterráneo de la Universidad de Granada y la Pontificia Universidad Católica de Valparaíso. 
despite being, by definition, an unknowable reality, the unstoppable increase of social diseases in recent times is self-evident. In the present article, I will deal with the role that the new information and communication technologies (NICTs) play in this regard, a key role to the extent that NICTs simulate in distans a world which is not a world at all. Enclosed this way, the current situation of the body and its manifestations in the contemporary development of telecommunications lie in uprooting and wandering, to the extent that the numerous devices of consummated technique have become more familiar than the actual world.

KEYwords: New information and communication technologies, «instant communication», "semiotic bombardment», uprooting, wandering.

\section{Introducción}

Si la filosofía puede definirse, a juicio de Nietzsche, como la crítica de la salud de una cultura, entonces no puede dejar de prestar oídos al rumor acechante de la nihilidad inherente a nuestro estilo de vida en la época de la técnica. Entendido como médico de la civilización, el sino del filósofo es, en efecto, ex-ponerse al descrédito, pues su ilustre tarea demanda renunciar a coincidir con lo expresado y distanciarse anacoréticamente para comprender su insospechado sentido. $Y$ es que, cuando la actual crisis financiera acapara una miríada de cuidados mientras todo lo sólido, parafraseando a Marx, se desvanece en el aire, la amenaza de la «superfluidad» se yergue impetuosa frente a toda voz discordante que ponga el acento en el carácter insípido de nuestra existencia.

Ahora bien, a pesar de que la decadencia espiritual de Occidente gobierna subrepticiamente desde la trastienda ontológica, sus mecanismos y fuerzas ciegas expanden su influencia a través de acuciantes enfermedades sociales que brillan con luz propia, como lo presente de lo ausente, en la inacabable noche del nihilismo tecnológico. En esta medida, la filosofía y las ciencias antroposociales están condenadas a entenderse con tal de averiguar la razón de ser del malestar preponderante en el mundo administrado por las incipientes tecnologías de la tele-comunicación, donde la precariedad y el desasosiego ocupan el noble asidero de la invención irruptiva y la intervención disruptiva, así como la urdimbre reticular que nos sostiene deviene, por desgracia, un flujo de co-existencias. 
En este contexto, la corporalidad y sus actitudes no constituyen ya una rémora que deba superarse con el objeto de pensar la vida, como ha sostenido la Modernidad desde la óptica que ofrece la definición cartesiana del ego como res cogitans, sino que representa una clave hermenéutica ineludible a la hora de aprehender la radiante vigencia del malestar que nos azota, pues la estructura ontológica que subyace a los agenciamientos que guarda con la alteridad lo ponen fehacientemente de manifiesto. De hecho, la instalación somática confortable conquistada mediante la implantación masiva de prótesis tecnológicas sobre la corporalidad modifica su disposición espacio-temporal de tal manera que, cuanto menos, da que pensar.

Desde este punto de vista, el objetivo del trabajo que nos ocupa se cifra en examinar, desde un enfoque interdisciplinar, las implicaciones patológicas vinculadas con nuestros sentidos corporales que presentan dos de los fenómenos intrincados entre sí más peligrosos del mundo tecnificado enteramente, alarmantes en la medida que se orientan a la conquista no sólo del espacio exterior, sino también del interior. Nos referimos a la "comunicación instantánea» [\$2] y el «bombardeo semiótico» [\$3], entendidos (a la heideggeriana) como dos modus operandi histórico-vitales del Ge-stell («estructura de emplazamiento», «armazón»), el modo de desvelarse la verdad o la destinación del sino que se cifra en la relación ontológica «demandante/dispuesto», esto es, la esencia metafísica de la era técnica y, por consiguiente, el germen de la decadencia occidental.

\section{Olvido pasivo del ser}

En los albores de su pródiga obra, Heidegger advierte que el «ser-ahí» (Dasein) es originariamente espacial bajo el modo de la «des-alejación», o sea, busca naturalmente, mediante los sentidos de la vista y el oído, trascender el horizonte local del acontecimiento. Pues bien, esta propensión consustancialmente protésica yace latente en el seno de las flamantes tecnologías de la tele-presencia, cuyas estrategias procedimentales irrumpen cuando el apéndice natural se torna insuficiente para mediatizar lo real, a modo de prolongación imaginaria de la lógica vital que entreteje nuestros esquemas somáticos:

Todas las formas de aumento de la velocidad a las que hoy cedemos más o menos forzosamente, impulsan a superar la lejanía. Con la «radio», por ejemplo, lleva hoy a cabo el «ser-ahí», por el camino de una ampliación del 
cotidiano mundo circundante, un des-alejamiento del «mundo» (Heidegger, 1927, 120).

Las diversas tecnologías telemáticas establecen, así pues, la comunicación instantánea a nivel planetario, desequilibrando las relaciones milenarias entre lo próximo y lo lejano de tal manera que hacen posible el establecimiento de continuidades entre lo ausente y lo presente al alcance de nuestras facultades gnoseológicas; como soñara la vanguardia futurista, el aquí se convierte entonces en otra parte cualquiera y, al final, termina siendo un "por todas partes» ${ }^{1}$. Desde este prisma, la célebre profecía mcluhiana de la «aldea global» posee un carácter ambiguo, a saber, la perfecta solidaridad entre globalización y aldeanización de la existencia. Como ilustra el entorno web cuando utilizamos la herramienta del blog con la esperanza de abrazar afinidades duraderas y vínculos recurrentes, cuanto más interconectados estamos en la red evanescente de cosmopolitismo abstracto, más nos refugiamos en la intimidad de los receptáculos aldeanos:

La $w w w$ sólo puede extenderse si deja que sus flujos se llenen de nichos. El oxímoron se reproduce por doquier: en Internet, los blogs devienen en chats y los chats se autodenominan «rincones», y así las ventanas flotantes que nos prometen la apertura global van privatizando los encuentros redirigiéndolos hacia el sempiterno café del vis a vis. La red es hoy un parque temático de la familia (Bayón, 2010, 217).

De aquí se siguen dos consecuencias nefastas para la salud. Por una parte, dichas tecnologías generan incertidumbre y miedo, puesto que ensanchan nuestro presente existencial hasta espacios inaccesibles ónticamente y, por ende, incrementan la complejidad de nuestras experiencias vitales hasta límites insospechados. Asimismo, olvidamos más, ya que el volumen de eventos a recordar aumenta exponencialmente (Sanfélix, 2011, 226-8). De tal suerte que, finalmente, no tenemos nada que ver con el pasado y, por consiguiente, ya no podemos aprender del recuerdo, pero tampoco sabemos qué nos cabe esperar, porque las expectativas se desmarcan progresivamente de nuestro horizonte de experiencia. La temporalidad deviene, por tanto, totalmente trastocada, se derrumba la cadena de transmisión entre las sucesivas generaciones y el tiempo descoyuntado se

${ }^{1}$ Existen evidencias empíricas que lo corroboran de manera fehaciente y, cuanto menos, curiosa. Por ejemplo, el físico Laszlo Barabasi (Universidad de Notre Dame, Indiana), uno de los pioneros en el estudio de las estructuras de sistemas complejos como las redes de nodos de comunicación en Internet, pondera que la mayoría de páginas webs pueden relacionarse mediante $18 \mathrm{o}$ 19 clics de media. http://www.rtve.es/tve/b/redes2007/semanal/prg312/lazlo.htm 
torna intempestivo, con menoscabo de la vinculación, antaño inextricable, entre memoria y esperanza.

Por otra parte, la representación lingüística del acontecimiento desprecia, como ocurre con la reproducción técnica de la obra de arte genuina, su íntima lejanía, esto es, su «aura», entendida como "la manifestación irrepetible de una lejanía (por cercana que pueda estar)»(Benjamin, 1990, 24), de manera tal que altera su naturaleza cualitativamente, desde su duración material hasta su testificación histórica. Y es que lo más cercano (Distanz) en un sistema de coordenadas cartesianas no tiene por qué encontrarse, en absoluto, menos lejos (Ferne) de nosotros. De hecho, la proximidad en lontananza o, si se quiere, el "des-alejamiento" (Entfernung) de la distancia (Abstand) resoluble técnicamente implica una cercanía mentirosa, porque hace pasar lo lejano por lo cercano desde un horizonte de percepción ampliado artificialmente a la luz del cual reduce, en la terminología de Heidegger, el acontecimiento del ser en su estado naciente a lo que está ahí «ante-los-ojos» o a la «disposición» del arbitrio humano ${ }^{2}$, hasta tal punto que «los lejanos planetas, por decirlo con Ser y tiempo, están más cercanos a nuestros ojos o más salidos de lo oculto que los circuitos encima de nuestro escritorio y en el interior de nuestros bolsillos» (Kittler, 2010, 112). En esta medida, desahucia la singularidad, el carácter único e irrepetible que determina su «aquí y ahora» o, mejor dicho, el «aura» de la cosa misma (su autenticidad irreductible), toda vez transformada en simulacros literalmente insustanciales, cuando no en meros productos virtuales:

El llamado «ser» se convierte así en algo susceptible de ser comunicado, y, por tanto, de separarse de sí mismo, de diferenciarse en el proceso de transmisión, recepción y apropiación, de distanciarse incluso de la propia materialidad al acceder al reino de la escritura digital, de una virtualidad donde cada fenómeno no sólo es enteramente sígnico, algo que designa otra

${ }^{2}$ El carácter falso de este fenómeno sólo puede entenderse en términos ontológicos. Y es que según el «nihilismo propio» postulado por el pensador alemán, la radical co-pertenencia entre ser y nada posee un carácter simultáneo, en virtud del cual el ser se des-cubre y en-cubre en el mismo acto porque, como potencia que abre, no puede permanecer en lo ente que ha abierto; pues bien, en la medida que debe retirarse, el ser se hurta a nuestra a mirada y, por tanto, es irrepresentable (al precio de entificarlo). Como envés de la misma moneda, el «nihilismo propio» implica la dimensión abismal (Ab-gründig) del ser, el cual recusa (Versagt) cualquier condición fundante porque toda fundamentación tendría que deponerlo hasta hacerlo ente. Huelga señalar que la noción heideggeriana de "nada» como fuente del ser rebasa su acepción cientificista como «lo absolutamente no-ente», ya que es más originaria que la negación y, por ende, trasciende la lógica universal (Heidegger, 2000, 96-7). 
cosa, que está en su lugar, sino algo definido por el despliegue de su alteridad íntima, por el desarrollo de una autonegación que puede y suele llevar a su concreción material (Aranzueque, 2010, 17).

En definitiva, el ser continúa impensado, mientras que la lejanía ha aumentado (en sentido cualitativo) exponencialmente, pues los estimulantes simulacros videoelectrónicos llamados a re-crear la articulación interna de la physis con el objeto de complementar nuestra fragmentada apercepción de la misma reifican, por muy ajustados y nítidos que nos parezcan, su insospechada figura (constitutivamente metamórfica) para controlarla y normalizarla, la domestican, la enervan y la desangran, por lo que está condenada a diseminarse, para deleite del «último hombre», en el devenir comercial del espacio telemático ${ }^{3}$.

En tal disposición de los términos, nos encontramos ante la siguiente paradoja: la técnica, operador antropológico de la distancia par excellence, realiza el sueño de una restitución de la inmediatez haciendo superflua la mediación, de modo que la máxima integración es simultánea con la máxima distancia. Pero si la transformación experimentada en el infospace a raíz del apogeo microelectrónico en la década de los cuarenta constituye, como observa Ramonet, la tercera gran revolución de la historia tras la escritura y la imprenta, es porque la superación virtual del espacio-tiempo no sólo ha transfigurado los atributos del acontecimiento en simples signos transferidos sino que también ha condicionado tanto nuestra cultura material como nuestra manera de pensar y de valorar ${ }^{4}$, hasta

\footnotetext{
3 El «des-alejamiento» del alejamiento consuma, de este modo, la metamorfosis moderna de la «forma-mercancía» en el principio constitutivo de todo lo óntico y la determinación estructural de todo lo que es en cuanto que es, ese proceso de erosión del ser que volatiliza nuestros goznes reduciendo la sociedad a labor y consumo, de forma que el mundo, como Arendt lamenta, pierde su carácter de mundo, es decir, su mundaneidad (Polo, 2009, 324). Con ocasión del Congreso «La reflexión política en la actualidad: Encuentro Internacional con Roberto Espósito», celebrado del 16 al 19 de septiembre de 2013 en Granada, hemos intentado mostrar, a la luz de la dialéctica communitas/immunitas desarrollada por el pensador napolitano, la traducción antropológica de semejante estallido secular y sus implicaciones patológicas en términos ortopédicos, a tenor de la constitución posmoderna de la identidad en el Capitalismo avanzado. El artículo correspondiente a dicho estudio se encuentra en vías de publicación por Isegoría. Revista de Filosofía Moral y Politica.

${ }^{4}$ Fiel a su oficio de viejo topo, cuando Marx advierte que los medios de comunicación son pharmakon (veneno y remedio), dado que pueden servir tanto a la destrucción del mundo (pues generan fuertes desequilibrios sociales asociados a la extensión de la pobreza, la explotación y la miseria de las masas urbanas), como a su salvación (ya que sientan las bases para la edificación de una sociedad libre y, por tanto, igualitaria), sugiere para la posteridad que el progreso técnico es el factor decisivo de la producción de cambios en la estructura social de clases y, por consiguiente,
} 
tal punto que los medios informativos se constituyen, elevados a la condición de «cuarto poder» (junto al ejecutivo, el legislativo y el judicial), como la principal fuente de las ficciones que articulan la opinión pública, en la medida que determinan los mapas cognitivos del mundo que trasciende nuestro entorno inmediato: «No vemos (...) la realidad (...) como es, sino como son nuestros lenguajes. Y nuestros lenguajes son nuestros medios de comunicación. Nuestros medios de comunicación son nuestras metáforas, nuestras metáforas crean el contenido de nuestra cultura" (Postman, 1985, 15). En este contexto, McLuhan suscribe que el medio se confunde con el mensaje, toda vez que la imagen constituye la autoridad epistémica más eminente y lo que contemplan nuestros ojos parece real e, incluso, verdadero 5 .

No son arbitrarias, por tanto, las diatribas vertidas contra la celebración posmoderna de una sociedad hiper-comunicada hasta el paroxismo, en la medida que alberga una óptica caleidoscópica y polifónica, un concierto comunicativo descentralizado y multiforme donde ninguna perspectiva posee más gravedad y preeminencia que las demás, en favor de las racionalidades limitadas, efímeras y contingentes, silenciadas hasta la fecha por los grandes relatos de la Modernidad y sus contenidos hieráticos, monolíticos y dogmáticos. No obstante, pensamos que debería mostrarse más cautela a la hora de alabar el potencial emancipador de la «sociedad de la comunicación», dado que si los medios informativos son el

en la superestructura política y estatal que se asienta sobre cada particular configuración de los modos de producción, así como en la ideología dominante que le confiere sentido y estabilidad. Hemos examinado la vigencia de las consideraciones marxistas ante la estructura reticular del Capitalismo en su fase posindustrial, en un estudio que verá la luz a mediados de 2014, en el número 16 de Astrolabio. Revista Internacional de Filosofía.

5 El progreso tecnológico ha otorgado ciertos soportes autónomos a la imagen, por concurso de los cuales se muestra más eficaz que el formato narrativo a la hora de construir y delimitar todo nuestro imaginario. No obstante, la imagen juega un papel fundamental en el devenir contemporáneo, como demuestran estudios de diversa índole. Cuando Debord analiza, con el florecimiento de la sociedad consumista, la industria del ocio y los medios de comunicación audiovisual como telón de fondo, la metamorfosis del concepto marxista de «alienación» en una expropiación de nuestro tiempo total de vida por mor de la ocupación del cuerpo social a cargo de la mercancía, señala que el «espectáculo» es la vida en la imagen, una imagen autonomizada cuya puesta en escena responde a la lógica del «simulacro» (entendido en términos de Baudrillard) pues, siendo representación de lo real, lo sustituye para ocupar su lugar (Debord, 1999). Por su parte, Sartori explora las consecuencias del imperio de la imagen a nivel antropológico para denunciar que el homo sapiens ha devenido homo videns, en detrimento de sus aptitudes intelectivas superiores, como la capacidad discursiva o el pensamiento reflexivo; se trata del "hombre del postpensamiento, incapaz de una reflexión abstracta y analítica, que cada vez balbucea más ante la demostración lógica y la deducción racional, pero a la vez fortalecido en el sentido del ver (el hombre ocular) y en el fantasear (mundos virtuales)» (Sartori, 1998, 146). 
único generador de sentido socialmente válido, cabe sospechar que la infoesfera, ese hipermundo de conectividad infinita, se encuentra diseñada y gestionada por los grupos capitalistas (de presión o ideopolíticos) y sus grandes corporaciones, a través de los mass media oligárquicos que, de hecho, monopolizan:

Contrariamente a quienes piensan que Internet realiza el ideal de una democracia directa y global, en la que los ciudadanos participan de manera directa en el gobierno a través de la nueva ágora electrónica (...), en su situación actual, las decisiones principales concernientes a la construcción de dicha urbe telemática escapan por completo al control de los telepolitas, es decir, de los/as ciudadanos/as de Telépolis (Echeverría, 2004, 173).

En cualquier caso, el modo psicosocial de percibir el espacio-tiempo bajo el signo del universo tecnocomunicativo ignora por completo, más allá de las viejas caracterizaciones que vertebraban el imaginario social en la época de la imagen del mundo, un presupuesto inevitable del pensar, a saber, que lo ente y el ser siempre sean descubiertos a partir de la diferencia y en ella:

El ser, en el sentido de la sobrevenida que desencubre (entbergenden Überkommnis), y lo ente como tal, en el sentido de la llegada que se encubre (sich bergenden Ankunft) se muestran como diferentes gracias a lo mismo, gracias a la inter-cisión (Unter-schid). La inter-cisión da lugar y mantiene separado a ese Entre (Zwischen) dentro del cual la sobrevenida y la llegada entran en relación, se separan y se reúnen. La diferencia de ser y ente, en cuanto inter-cisión entre la sobrevenida y la llegada, es la resolución (Austrag) desencubridora y encubridora de ambas. En la resolución reina el claro de lo que se cierra velándose y da lugar a la separación y la reunión de la sobrevenida y la llegada (Heidegger, 1988, 134).

Se trata, efectivamente, de la ineludible «diferencia óntico-ontológica» entre la dimensión vertical del acontecimiento de venir a presencia un mundo u horizonte de sentido, tan sólo experimentable páticamente desde la perspectiva «sera-la-mano» (Zuhandensein), y la dimensión horizontal del mundo de sentido ya presente y representable en una superficie homogénea de píxeles desde el enfoque «ser-ante-los-ojos» (Vorhandensein), en lo que constituye el «máximo olvido del ser», la consumación del «nibilismo impropio».

Como consecuencia de ello, tiene lugar, para hablar con Weber, un "desencantamiento del mundo" en función del cual abandonamos su insigne faceta como 
objeto de aprendizaje, mientras que lo extraño ha dejado, paradójicamente, de extrañarnos, y sus fascinantes zonas de sombra se exfolian, toda vez importadas y normalizadas en lo propio con tal de procurarles una cercanía desinfectada de sus efervescencias y mestizajes, en una inquietante atmósfera de banalidad, indolencia, apatía y creciente hiperfobia, esa sensación velada de catástrofe inminente pero indeterminada que, alimentada sistemáticamente por los medios de comunicación, flota abstractamente en nuestra conciencia del porvenir hasta producirnos simpatía, en lo que constituye un caldo de cultivo de graves problemas morales, como son la "ética a distancia en la época del mando a distancia televisivo» o la "complicidad involuntaria entre el terror y los medios» (Safranski, 2004, 82-5).

\section{Olvido activo del ser}

La interminable lluvia de signos y estímulos sin ligazón que nos asaltan y agitan hasta el paroxismo ${ }^{6}$ se presenta ante nosotros como un recurso subrepticio crucial de la plétora que los mass media implementan, toda vez capturada la distancia, a fin de organizar la vida al modo de un sistema postal, según el modelo general de la cibernética de Wiener ${ }^{7}$. Desde una óptica heideggeriana se trata, en efecto, de un modus operandi obstinado por dirigir y asegurar la atención del espectador hasta el prurito de pro-ducirlo como mera "existencia» (Bestand), en la medida que le desafía a solicitar ancilarmente todo lo existente como estímulos y asumir, cual correa de transmisión, el protagonismo de la (i)lógica implacable del "producir por producir» como sujeto de toda «usura»:

${ }^{6}$ Las estadísticas más recientes reflejan que un ciudadano europeo recibe alrededor de 3.000 impactos publicitarios diarios (eventos, anuncios, envases, product placement, etc.), mientras que los americanos reciben unos 5.000. http://www.grupcies.com/boletin/images/stories/PDFBoletin/ArticuloIII Edic 47.pdf

7 Si bien los "principios de la propaganda» de Goebbels siguen vigentes, es evidente que han conocido rupturas y complementos de todo tipo. No nos pasa desapercibido que las estrategias más tradicionales al respecto, como la manipulación, apuntan últimamente hacia la colonización y la configuración de nuestros apetitos más íntimos bajo el signo del neuromarketing, estudiando los efectos de la publicidad y otros actos comunicativos en el cerebro con el afán de predecir la conducta del consumidor mediante mediciones psicofisiológicas periféricas y centrales (ritmo cardíaco, respuesta galvánica de la piel, etc.) con el rigor científico de la neurociencia. Pero a pesar del carácter sofisticado de la nueva investigación de mercados, estamos convencidos que el «bombardeo semiótico» es el recurso más significativo a la hora de evaluar las implicaciones morbosas de nuestro modo de vida, con lo cual abogamos por centrarnos en sus entresijos con tal de no rebasar los límites del presente trabajo. 
Hoy en día la excitabilidad constituye el primer deber del ciudadano. Por esta razón ya no necesitamos ningún servicio militar obligatorio. Lo que sí resulta exigible es el servicio a los temas generales, es decir, la disposición individual a desempeñar la función como conductor del estímulo en el marco de las psicosis colectivas pertinentes. Se exige, pues, estar disponible en la movilización de las consignas (Sloterdijk; Heinrichs, 2004, 85).

A fin de lograr la máxima eficiencia al respecto, los medios audiovisuales buscan saturar nuestra atención (entendida como la capacidad individual de experimentar creativamente un objeto de cara a realizar proyecciones ficcionales), por medio de un encantamiento hipnótico practicado sobre un trasfondo darwinista donde realizan el atributo teológico de la ubicuidad: como Dios, saturan lo real con su presencia, invisible pero omnipotente. En esta medida, nos suministran el mundo por obra y gracia de su «licuefacción» (no sólo a costa de la forma-cosa, como apunta Bauman, sino también de la cosa misma), en lo que constituye una invasión de los cuerpos (en cuanto cápsulas) en función de la cual son domesticados mediante shocks, generando una especie de distracción excitada que desemboca en sentimientos de histeria y pánico, desorden por déficit de atención y dislexia:

Primero está cada uno concentrado, comprimido en su trabajo y en las restantes actividades de la vida; cuando cesa esa presión, en el llamado tiempo libre, los liberados de la presión estallan y se precipitan en mil imágenes de acontecimientos que, propiamente, no los afectan. En verdad son las imágenes las que se precipitan sobre ellos. (...) Estímulos que de suyo son ocasionales, se disponen de forma duradera y buscan ocasiones siempre nuevas (Safranski, 2004, 81-2).

Acostumbrados ya a los estímulos (aparentemente caóticos, pero consistentes en virtud de la dicotomía binaria de los bits que cifran su curso, así como la discontinuidad eléctrica que conforma su base material), dejamos que la voluntad se disuelva impertérritamente en el funcionamiento imparable de la maquinaria (Machenschaft) por mor del sistema de ajustes y regulaciones que integra, hasta el extremo que sólo prestamos oídos y tenemos ojos para el mundo administrado. Más aún, nuestra hiperatención monotemática tiene un alcance adictivo, en tanto que mostramos una necesidad impropia de consumir ad infinitum dosis renovadas de reclamos, imágenes, seducciones y posibilidades, no ya en términos de 
percepción sino de simple absorción ${ }^{8}$. Así pues, la actual idolatría de la realidad supone que el mundo se define como estímulo o, si se prefiere, como «desinhibidor pulsional», lo cual levanta sospechas sobre cierta regresión animal de la especie humana en el sentido de una volatilización, toda vez centrada instrumentalmente, de la excentricidad que le es propia.

Desde un punto de vista antropológico, la plebeya pleitesía ante el cortejo triunfal de la hiper-estimulación semiótica radica en un rebasamiento, a la velocidad de la luz, de los límites individuales (Safranski, 2004, 79-81). Más allá de la «biopolítica» foucaultiana, la administración de la vida designa, bajo esta luz, un cuidado de la muerte o "tanatopolítica», mientras que el biologicismo contemporáneo no se cifra, como piensa Agamben, en la «nuda vida» (zoé), sino en la «nuda muerte». Según Safranski, todo individuo comprende dos esferas coordinadas entre sí: los sentidos, que reciben estímulos, y la acción, que les da salida. Ahora bien, dado que el cuerpo humano no es sino la «brecha» por donde penetra lo otro de sí (o sea, el «claro» donde el mundo tiene su entrada y aparece), sus sentidos se encuentran, por así decirlo, demasiado abiertos, y la coordinación entre ambas instancias deja mucho que desear.

En este contexto, nos vemos abocados a elaborar un sistema cultural de filtros a modo de armadura inmunizante frente a los envites abusadores que desbordan nuestros límites con tal de conquistar un campo de vida propio, en base a procesos irreverentes de individuación capaces de poner entre paréntesis el status quo de la técnica consumada y sus falsos prestigios, bajo cuya égida prospera la actual vegetación humana'. Se trata, por ejemplo, de cortocircuitar

${ }^{8}$ Como muestra Berardi (2007), los receptores humanos intentan asimilar tal caleidoscopio abigarrado de pseudosignificados difusos mediante procesos de sobreinclusión (espirales asociativas, conexiones a-significantes, etc.). En la medida que poseen, empero, un carácter detonante (flash) y son, asimismo, tendencialmente infinitos hasta alcanzar el rumor blanco de lo irrelevante y lo indescifrable, los flujos semióticos no permiten discurrir sobre ellos. De aquí se siguen patologías sociocomunicativas de cuya amenaza no podemos ya librarnos, pues siempre están ahí, al acecho. El cibertiempo marca un límite insalvable para la elaboración emocional con los otros, y todo lo somete al vértigo del decir y del contar, ese «éxtasis de la comunicación» que nivela el espacio, a pesar de su apariencia polifónica, en el eco siniestro de las «habladurías». Entretanto, el otro deja de ser «objeto de solicitud» (Fürsorge), de tal manera que la reducción del espacio físico a manos de la técnica se traduce, paradójicamente, en una ampliación exponencial del espacio interhumano, como atestigua la expansión egocéntrica del espacio individual y la tendencia al aislamiento.

9 No se trata de condenar los dispositivos técnicos de la información como obra del diablo sino, como Nietzsche sugiere, "convertirnos nuevamente en buenos vecinos de las cosas más cercanas», es decir, habitar el aquí y ahora del extravío y consumir estímulos con moderación, dejar que descansen en sí mismos de forma que podamos desembarazarnos (Loslassen) de ellos como 
los inputs estresantes que recibimos, actuar con menor rapidez, posibilitar el capricho, fomentar el sentido de lo local, mostrar capacidad para desconectar y, en resumen: «Demostrar que un sujeto puede ser interruptor de la información, y no un simple canal de transmisión que sirve de paso a las epidemias temáticas y oleadas de excitación» (Sloterdijk; Heinrichs, 2004, 88). Lamentablemente, el aparato informativo-publicitario y su fúnebre lógica terminan abortando, con el afán de fabricar sujetos excitados permanentemente, tales expectativas:

El círculo de los sentidos, ampliado artificialmente a través de la prótesis mediática, se ha desligado por completo del círculo de la acción. Ya no podemos reaccionar de forma adecuada a través de la acción, ni somos capaces de traducir el estímulo en acción y de darle salida a través de ella (Safranski, 2004, 81).

Así entendidas, las nuevas tecnologías de la información no ensanchan los horizontes del hombre sino que, más bien, reducen su radical apertura al mundo (Weltoffenheit) al aturdimiento o acaparamiento y, por ende, suspenden la potestas sui para no ser co-extensivo totalmente al mundo, expansionarse allende su linde ontológica y abrazar disposiciones inéditas, la potencialidad física de que su mirada ex-céntrica pro-yecte hacia una tierra ignota, para constituirse como "dividuo» en su devenir, la ex-tradición nomadológica que experimenta respecto al mundo por mor de la perplejidad o calma hechizada del «extrañamiento» (Entfremdung), esa tensión metamórfica insuprimible simbolizada por Hermes, el dios amigo de los caminantes para el que no existen cerraduras, recinto ni clausura ${ }^{10}$.

algo que no nos compete propiamente, pues no agotan la diferencia que somos. En la línea de la «jovialidad» nietzscheana, Heidegger denomina «serenidad» (Gelassenheit) a la actitud por la que habitamos la jungla del infospace pero al abrigo de su amenaza, y la urdimbre de signos que se entrecruzan y solapan a nuestro alrededor se encuentra, a su vez, dentro y fuera de nuestra vida. En este sentido, el relato Reencuentro inesperado de Hebel pone de manifiesto lúcidamente lo que en geometría resulta absurdo, a saber, que el círculo menor de cada biografía contenga el círculo mayor de la infoesfera sin explosionarlo, como puesto entre dos guiones, enlazado tenuemente por un singular «mientras tanto» (Safranski, 2004, 119-20).

${ }^{10}$ Este «ser-en-la-imposibilidad» constituye lo patológico en su sentido más radical (May, 1967, 64-5), en cuanto que decreta la claudicación de la responsabilidad ontológico-existencial heideggeriana de hacer-por-ser que hunde sus raíces en el carácter abismal del ser, de manera que desahucia la dignidad humana (Della Mirandolla, 1994, 122-3) y consolida, para más escarnio, la mediocridad y el allanamiento de las sociedades superadministradas en nombre del neo-liberalismo estatuido. 
Dado que el prurito reificador del aturdimiento conlleva cierta apertura sin desvelamiento de lo ente y, por consiguiente, impide que nos sea revelado en cuanto tal, el mundo se trueca para nosotros, como ocurre en el caso del animal, en una materia dada a priori, cuando lo específicamente humano es tener solamente un a priori formal a propósito. Como consecuencia de ello, estamos en el mundo, parafraseando a Bataille, "como el agua en el agua», de manera tal que el «ser-en-el-mundo», nacido para nacer, anda al borde de despeñarse allí donde su centricidad se des-centra del mundo para tornarse "ser-frente-al-mundo", pues ha roto la nervadura o el quicio que permite experimentar la interpelación de la alteridad con vistas a crear una tierra abierta, singular y múltiple, en cuya alborada la tenaza de la planificación y computación, de la organización y de la empresa automatizada no tenga la última palabra.

Con el objeto de paliar el malestar y la angustia de la vacuidad, este ser sin atributos, huérfano de vínculos con el mundo, afronta la desertización de su centricidad mediante una autocontradicción vital en virtud de la cual se abandona o, mejor aún, «acontece en su impropiedad»: «Es (...) un falseamiento interno que la obliga a ser sólo en cuanto apócrifa, una ficcionalización de sì» (Sáez, 2011, 76). Hablamos de una existencia errática que deambula des-pedida (sin patria), obsesionada con amalgamarlo todo en la dimensión instrumental de la presencia manipulable y sus «velocidades infinitas que se confunden con la nada incolora que recorren, sin naturaleza ni pensamiento» (Deleuze; Guattari, 1991, 202). De hecho, lejos de los problemas de acceso iniciales conocidos como «brecha tecnológica», puede considerarse un privilegio a día de hoy no tener que acudir a la red o ver lo más próximo en lugar de la tele-visión, en lo que constituye un proceso gradual y expansivo de "pantallización» de la vida que conduce hic et nunc a la pantalla, ese «no-lugar» especulativo que refleja, si bien lívidamente, la faz del mundo, todas sus edades, todas sus mañanas.

Así pues, el «desarraigo» o «desasimiento» trae consigo, en la terminología de Ser y Tiempo, una "caída en la inautenticidad» o «desistimiento» que representa, como delatan ciertos procesos neuróticos, una huida hacia delante a la desesperada, una organización compulsiva del vacio que se traduce en disposiciones depresógenas tan generalizadas como la hiperfagia, la movilidad insuficiente, el sueño de instauración tardía, la obesidad o la tecnoadicción (Alonso, 2011, 55-8). Con todo, lo más inhóspito es que, a pesar del bullicio vertiginoso y su actividad desaforada, no cambia nada esencial o cualitativo, pues sólo tienen lugar novedades superfluas con aires de pensamiento, ilusiones mágicas y sutiles de creatividad que ocultan la realidad de la penuria y su cobarde necesidad de encubrirse: «Es 
un vértigo de acción sustentado, paradójicamente, en la parálisis, un tráfago del hacer y del transitar que pivota sobre la inmovilidad» (Sáez, 2007, 119).

Desde luego, el fenómeno de la «avidez de novedades» (Neugier) ilustra modélicamente la distracción del vacio en la "sociedad estacionaria» y su esperpéntica perspectiva, entendido como un impulso por hacer de lo nuevo lo mejor en aras del placer de ver, en contraste con el deseo de aprender y saber propio del «cuidado» (Sorge):

El «ser ahí» se deja arrastrar únicamente por el aspecto del mundo, una forma de ser en que se cura de quedar exento de sí mismo en cuanto «ser en el mundo», exento del ser cabe lo inmediata y cotidianamente «a la mano» (Heidegger, 1994, 191).

Este acuciante fenómeno conlleva, de un lado, síntomas tan mórbidos como ausencia de demora ${ }^{11}$, excitación e inquietud ${ }^{12}$ y esquizotopía o falta de paradero ${ }^{13}$. De otro lado, consolida el monopolio del «pensamiento calculador» en detrimento del «pensamiento meditativo» (Heidegger, 1989, 15-30), esa función de la libertad que anhela lo infinito en el plano de la existencia, lo invisible de lo visible o, como Heidegger diría, el sentido que impera en todo cuanto es.

${ }^{11}$ La potenciación de la prisa o estrés del tiempo hasta en los momentos dedicados al ocio es una antesala de la depresión por agotamiento emocional, ya que suscita neurastenia, a saber, un «tipo de neurosis caracterizado por una gran sensación de cansancio y debilidad, además de miedo y tristeza, ante cualquier esfuerzo físico o intelectual» (Barroso, 2011, 111). A nivel político, genera una especie de manía persecutoria, paranoias, alucinaciones y delirios etnógenos de unidad, afinidad o coherencia que explican, a costa de la ética y la ideología política, la síntesis de las naciones modernas (véase el caso de Serbia), entendidas como «comunidades del autoestrés» (Sloterdijk; Heinrichs, 2004, 79-85).

${ }_{12}$ En la medida que requiere un tiempo de aprendizaje inasumible si nos atenemos a la obsolescencia fulgurante y la aceleración disolvente que caracterizan la dýnamis tecno-nihilista, la exigencia de adaptación que supone el advenimiento de un instrumento técnico produce ansiedad y, a la postre, un vacio adaptativo abierto a la melancolía y la depresión, en lo que constituye la justificación psicológica de la prosperidad alcanzada por las fobias existenciales y neuróticas en una humanidad permanente enajenada, es decir, funcionando con el motor de adaptación al máximo para integrarse en situaciones no elegidas ni vividas como propias (Alonso, 2011, 55).

13 Por mucho que podamos comunicarnos y viajar globalmente, es imposible habitar un «mundo sin aquí». Así pues, la "avidez de novedades» implica la quiebra de la escucha necesaria, como enseña la fenomenología (desde la versión idealista de la epojé concebida por Husserl hasta su torsión existencial como disposición pastoril en la filosofía de Heidegger), para acceder a la textura ontológica de las cosas mismas en su autodonación, ya que el sazonamiento emocional de la vinculación a un lugar propio (Heimat) es directamente proporcional a la capacidad de apertura al mundo y la disposición a ella (Safranski, 2004, 24-5). 
Y es que, en la época de la técnica, el cálculo no designa ya la simple práctica del saber matemático sino que designa una ley fundamental del comportamiento humano que no contempla más realidad que la computada a modo de transacciones, de forma que todo cambio espontáneo, ligado al crecimiento de la vida espiritual, es rechazado, expulsado o, peor aún, condenado a la «superfluidad». Sin detenerse nunca a meditar, el pensar que calcula posibilidades siempre nuevas, con perspectivas cada vez más ricas y económicas, hunde sus raíces, empero, en un fenómeno de mayor alcance, a saber, la reducción moderna de la acción (en cuanto fuerza "vertical», como reza su etimología) a mera operatividad (Sáez, 2007, 60-1). Además de la proletarización del pensamiento naciente, el pre-dominio del pensar que calcula conlleva una pérdida de la experiencia o anemia de realidad que genera, por mor de cierta inseguridad existencial ${ }^{14}$, acuciantes patologías del criterio, cuyo alcance estriba en la ausencia de juicio y discernimiento de cara a poner medida o establecer reglas mínimas en la multiplicidad.

\section{Conclusión}

En resumen, tenemos que el triunfo ecuménico de la instalación manipulable del mundo científico-técnico, junto al orden socio-cultural congruente con él, convierten nuestra anatomía en un patético guińapo de músculos a merced de su poder omnímodo, cuya sola circulación otorga el brillo del ser a lo que transita en su seno, tiende a la apropiación y omnidifusión incorpórea y a domicilio de la distancia antaño sagrada (pese al abismo insalvable que media, como advierte Benjamin, entre lo propio o el «aura», de un lado y sus vestigios o «huellas», de otro), sólo obedece al insaciable perfeccionamiento de sí («producir por producir», más allá de las necesidades concretas), y tiene un extraño carácter holista por el cual recorre la piel del orbe a través de suntuosas autopistas de la información

14 «Es un sentimiento de inestabilidad, de que no existe un punto fijo en el que situar la confianza» (Bauman, 2008, 43). Este pathos, marcado por la precariedad, la desmoralización y la intemperie, supone que el ámbito de las creencias («campo de realidad», en el lenguaje de Zubiri) donde descansa nuestra vida cotidiana se derrumba, ya que se tornan modas incapaces de proporcionar, dado su carácter efímero, sistemas de referencia a la razón. Más aún, si aceptamos que un soporte axiológico sólido es conditio sine qua non para discurrir por la vida con equilibrio y salud mental, el diagnóstico del ocaso de los valores y la desorientación vital concomitante (Ortega, 2003) reviste, efectivamente, un interés inaudito para una crítica de patologías. Por lo demás, la inseguridad existencial fomenta la tendencia interna de la sociedad a la hiperfobia, junto a los niveles excesivos de seguridad física y el «aburrimiento profundo» (tiefe Langeweile), ese temple de ánimo, profundo como una tumba, que oscila en los abismos de la existencia cual niebla silente (Barroso, 2011, 107-9). 
ópticas y microelectrónicas capaces de condensar y registrar todos los tiempos (a costa del oscurecimiento del mundo). De aquí que el usuario, hablando en términos telefónicos, se encuentre apagado o fuera de cobertura por definición aunque, paradójicamente, siempre se halla localizable, como atestigua la función de stand by que poseen los teléfonos móviles.

Desde esta óptica, el nihilismo tecnológico que nos hospeda entre sus eternos brazos empobrece nuestra vitalidad sensorial de un modo tal que nos arrastra inexorablemente hasta la esencial retirada de la posibilidad de percibir algo como siendo algo, dando lugar a una "ex-sistencia» (Ek-sistenz) encarcelada en el tremendo «caosmos» informacional contemporáneo, despreocupada en absoluto por la verdad del ser y ocupada en el recreo inaudito de su errancia hasta el paroxismo. Sin embargo, a pesar de la pobreza de mundo que le caracteriza y despojado como está de la experiencia de lo inédito, el autómata animado de la edad del plástico insiste y persiste en una única interpelación, a saber, la irresistible exuberancia de lo meramente disponible como tal y en su decurso, hace oídos sordos a las interpelaciones de su propio devenir e, incluso, presume ciegamente, como si de un prócer se tratara, de ser el amo y señor de la Tierra.

\section{BIBLIOGRAFÍA}

Alonso, F. (2011). «Factores determinantes en el incremento del trastorno depresivo en los últimos sesenta años», en Sáez, L., Pérez, P. y Hoyos, I. (eds.), Occidente enfermo. Filosofía y Patologías de Civilización, Múnich: Grin, 16-70

Aranzueque, G. (2010). «Introducción. Ontología y movilidad», en Aranzueque, G. (ed.), Ontología de la distancia: Filosofias de la comunicación en la era telemática, Madrid: Abada, 7-19

Barroso, O. (2011). «Patologías del criterio en la era de la globalización», en Sáez, L., Pérez, P. y Hoyos, I. (eds.), Occidente enfermo. Filosofia y Patologias de Civilización, Múnich: Grin, 93-113

Bauman, Z. (2008). Múltiples culturas, una sola humanidad, Buenos Aires: Katz

BAYóN, F. (2010), «La sociedad extrañada: Retóricas de la inmunidad», en Arribas, S., Cano, G. y Ugarte, J. (eds.), Hacer vivir, dejar morir. Biopolitica y capitalismo, Madrid: Arbor, 247-72 
Benjamin, W. (1990). "La obra de arte en la época de su reproductividad técnica», en Discursos interrumpidos I, Madrid: Taurus, 17-57

Berardi, F. (2007). «Patologías de la hiperexpresión», Archipiélago: Cuadernos de critica de la cultura, 76, 55-63

Debord, G. (1999). La sociedad del espectáculo, Valencia: Pretextos

Della Mirandolla, G. P. (1994). «Discurso sobre la dignidad del hombre», en Rodríguez, P. (ed.), Humanismo y Renacimiento, Madrid: Alianza, 121-53

Deleuze, G.; Guattari, F. (2005). ¿Qué es filosofía?, Barcelona: Anagrama

Echeverría, J. (2004). Los señores del aire: Telépolis y el tercer entorno, Barcelona: Destino

Heidegger, M. (1994). El Ser y el Tiempo, Madrid: FCE

- (1988). «La constitución onto-teo-lógica de la metafísica», en Identidad y diferencia, Barcelona: Anthropos, 99-158

- (1989). Serenidad, Barcelona: Serbal

— (2000). «¿Qué es metafísica?», en Hitos, Madrid: Alianza, 93-109

Kittler, F. (2010). «El des-alejar», en Aranzueque, G. (ed.), Ontología de la distancia: filosofias de la comunicación en la era telemática, Madrid: Abada, 99-119

May, R. (1967). «Contribuciones de la psicoterapia existencial», en May, R., Angel, E. y Ellenberger, H. (eds.), Existencia. Nueva dimensión en psiquiatría y psicología, Madrid: Gredos, 58-122

Ortega, J. (2003). El tema de nuestro tiempo, Madrid: Espasa-Calpe

Polo, J. (2009), «Postmodernidad consumista y nihilismo de la mercancía», Éndoxa: Series Filosóficas, 23, 310-57

Postman, N. (1985). Amusing Ourselves to Death: Public Discourse in the Age of Show Business, New York: Penguin Books

SÁEz, L. (2007). «Ficcionalización del mundo. Aportaciones para una crítica de patologías sociales", Revista de Filosofía Universidad de Costa Rica, XLV, 115-6, 57-69

- (2011). «Enfermedades de Occidente. Patologías actuales del vacío desde el nexo entre filosofía y psicopatología», en Sáez, L., Pérez, P. y Hoyos, I. (eds.), Occidente enfermo. Filosofía y Patologías de Civilización, Múnich: Grin, 71-92

SAFRANSKI, R. (2004). ¿Cuánta globalización podemos soportar?, Barcelona: Tusquets

SANfÉLIX, V. (2011). "Terror y globalización», en Ávila, R., Ruiz, E. y Castillo, J. M. (eds.), Miradas a los otros. Dioses, culturas y civilizaciones, Madrid: Arena Libros, 217-35

SARtori, G. (1998). Homo videns: la sociedad teledirigida, Madrid: Taurus 
Sloterdijk, P.; Heinrichs, H. J. (2004). El sol y la muerte. Investigaciones dialógicas, Madrid: Siruela

\section{REFERENCIAS ELECTRÓNICAS}

http://www.rtve.es/tve/b/redes2007/semanal/prg312/lazlo.htm [Consulta 13 de septiembre de 2012]

http://www.grupcies.com/boletin/images/stories/PDFBoletin/ArticuloIII_Edic 47. pdf [Consulta 18 de septiembre de 2012]

Recibido: $12 / 12 / 2013$

Aceptado: 3/02/2014

Este trabajo se encuentra bajo una licencia de Creative Commons ReconocimientoNoComercial-SinObraDerivada 4.0

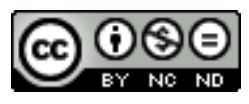

